\title{
Studies on Steroid Fever
}

\section{PRODUCTION OF LEUKOCYTE PYROGEN IN VITRO BY ETIOCHOLANOLONE}

\author{
Phyllis Bodel and Morris Dillard \\ From the Department of Internal Medicine, Yale University School of \\ Medicine, New Haven, Connecticut
}

\begin{abstract}
A B S T R A C T When a serum-buffer solution of etiocholanolone is incubated with human blood leukocytes in vitro, a pyrogen is released. Like endogenous pyrogen of leukocyte origin, this pyrogen produces prompt monophasic fevers in rabbits, does not induce fever tolerance when given daily, and is inactivated by trypsin. In many respects, the characteristics of the in vitro reaction resemble experimental steroid-induced fever. For example, release of pyrogen varies directly with the concentration of steroid. $4-8 \mathrm{hr}$ of contact between steroid and leukocyte is required for activation of the cell. Rabbit leukocytes are not activated by etiocholanolone. Finally, androsterone, the $5 \alpha$ isomer of etiocholanolone, does not induce pyrogen release in vitro. These studies suggest that experimental steroid fever in man may be mediated by an endogenous pyrogen released from leukocytes.
\end{abstract}

\section{INTRODUCTION}

In 1956 it was reported that the intramuscular injection of a naturally occurring steroid hormone metabolite, etiocholanolone ( $3 \alpha$-hydroxyetiocholane-17-one), produced fever in man (1). Many subsequent experiments have since confirmed these findings and have provided additional information characterizing this response $(2,3)$.

Dr. Bodel is a Research Associate in Medicine. Dr. Dillard is an Assistant Professor of Medicine. Address requests for reprints to Dr. Phyllis Bodel, Yale University School of Medicine, 333 Cedar Street, New Haven, Conn. 06520.

Received for publication 5 June 1967 and in revised form 11 September 1967.
Tests with etiocholanolone and with steroids closely related in structure indicate that these agents produce fever only in man (4). Unlike fever induced by bacterial endotoxin, which develops within $1-1 \frac{1}{2} \mathrm{hr}$ after intravenous injection, there is a delay of 4-6 hr before the onset of steroid-induced fever, which may then last for $12 \mathrm{hr}$ or more (2). Pyrogenic activity of various steroids is related to their particular structural features (5), and appears to depend on a $5 \beta$ configuration (1).

Although local inflammation characteristically follows intramuscular injection of the pyrogenic steroids (6), and increased numbers of granulocytes appear in the blood at the time of the fever (2), the unusual features of steroid fever have led to the suggestion that these agents elevate temperature by a mechanism that does not involve the white cell, and therefore, steroid fever differs from fevers caused by various microbes and their products (7). Since there is evidence that certain types of periodic fever are associated with abnormal steroid metabolism $(8,9)$, it seemed worthwhile to look for the pathways for the pyrogenic action of etiocholanolone.

Recent observations have demonstrated that human leukocyte pyrogen, produced in vitro by incubation of blood leukocytes with endotoxin or heat-killed staphylococci, can be detected by ininjection into rabbits (10). Similar experiments, therefore, seemed appropriate in order to examine possible effects of etiocholanolone on pyrogen production by human blood leukocytes. 


\section{METHODS}

All glassware and standard reagents were rendered sterile and pyrogen-free by heating at $160^{\circ} \mathrm{C}$ or autoclaving for $2 \mathrm{hr}$. Tris buffer and enzyme preparations were filtered through an ultra-fine sintered glass filter and tested for pyrogenicity. Techniques for injection of rabbits and temperature recording have been reported previously (11). In early experiments, each rabbit received injections for only 2 or 3 consecutive days to avoid fevers arising from sensitization to human materials. Later it was found that hypersensitivity fevers did not occur in most rabbits until after 5 days of injections, as long as exposure to human materials was limited to supernatants of incubated leukocytes as described below.

Preparation of leukocytes. $100 \mathrm{ml}$ of blood containing $10 \mathrm{U}$ of heparin per $\mathrm{ml}$ was obtained from normal male volunteers. To this was added $200 \mathrm{ml}$ of $3 \%$ dextran ${ }^{1}$ in saline. After 20-30 min at room temperature, the leukocyte-rich supernatant was removed, centrifuged at $300 \mathrm{~g}$ for $15 \mathrm{~min}$, and the cell buttons were washed once with Krebs-Ringer phosphate (KRP) buffer, ${ }^{2}$ containing heparin, $10 \mathrm{U} / \mathrm{ml}$. After a second centrifugation, most remaining red cells were lysed by brief exposure to distilled water (12) and the leukocytes were washed once more with heparinized buffer and centrifuged. Leukocytes were then counted on a Coulter Particle Counter and adjusted to a concentration of $9-10 \times 10^{7}$ per ml.

Monocytes. The method of Bennett and Cohn (13) was used to prepare from normal blood a leukocyte fraction which contained predominantly mononuclear cells. $100 \mathrm{ml}$ of heparinized blood was mixed with $200 \mathrm{ml}$ of $3 \%$ dextran in saline, and the red cells were allowed to settle for 20-30 min. The supernatant was then removed, centrifuged at $300 \mathrm{~g}$ for $15 \mathrm{~min}$, and the cell buttons were resuspended in $5-8 \mathrm{ml}$ of $25 \%$ human serum albumin. ${ }^{3}$ This mixture was centrifuged for $36 \mathrm{~min}$ at $12^{\circ} \mathrm{C}$ at 2400 $g$. The cells at the top of the tubes were carefully removed, along with a few milliliters of albumin, $30 \mathrm{ml}$ of heparinized KRP buffer was added, and the suspension was centrifuged again at $300 \mathrm{~g}$ for $15 \mathrm{~min}$. The cells were then suspended in a few milliliters of buffer or autologous serum, and a cell count and differential were performed. $50-70 \%$ of the leukocytes were monocytes, the rest being mostly small lymphocytes. Polymorphonuclear leukocytes varied from $<1$ to $15 \%$.

Steroids. Etiocholanolone (Mann Research Labs., Inc., New York) was autoclaved for $1 \frac{1 / 2-2}{\mathrm{hr}}$ in an Erlenmeyer flask. KRP buffer was added and the flask was shaken overnight in a Dubnoff incubator at $37^{\circ} \mathrm{C}$. The saturated solution was then passed through an ultrafine sintered glass filter, and the filtrate was stored at $4^{\circ} \mathrm{C}$. Solutions of androsterone were prepared in the same way. Identification and characterization of the steroids

1 Dextran, M.W. 100,000-200,000 Nutritional Biochemicals Corp., Cleveland, Ohio.

2 Modified to contain 15 the concentrations of $\mathrm{Ca}^{++}$and $\mathrm{Mg}^{++}$, to prevent precipitation.

3 Normal human serum albumin, salt-poor, American National Red Cross. were performed using various chromatographic procedures. A $96 \%$ methanol:heptane system was used for paper chromatography. The column method employed the gradient elution technique of Lakshmanan and Lieberman (14). Gas-liquid chromatography was performed on a 1\% XE-60 coating of Celite (mesh 100-120) in a $6 \mathrm{ft}$ by $4 \mathrm{~mm}$ coiled column with a flame detector. Fach procedure was standardized employing known steroids whose purity was demonstrated by melting point, mixed melting point, and infrared spectroscopy. Steroid concentrations were determined by using the Zimmerman colorimetric technique (15). Solutions of radioactive etiocholanolone and androsterone of high specific activity, prepared by the Wilzbach exchange method (16), were made in an identical manner, and alicuots were added to some experimsents in order to follow any small changes in the steroids during incubation.

Incubation. $50-\mathrm{ml}$ Erlenmeyer flasks contained $1 \mathrm{ml}$ of the leukocyte preparation, $6 \mathrm{ml}$ of heparinized KRP buffer or a buffer solution of etiocholanolone, $1.2 \mathrm{ml}$ of autologous serum, $1.5 \mathrm{mg}$ of glucose per $\mathrm{ml}$, and $6000 \mathrm{U}$ of penicillin. The total inculation volume in each flask was 8-9 ml. The flasks were shaken on a Dubnoff incubator at $37^{\circ} \mathrm{C}$ for $2-3 \mathrm{hr}$, and then placed in a stationary incubator at $37^{\circ} \mathrm{C}$ overnight. After about $18 \mathrm{hr}$ of incubation, the flask contents were removed, centrifuged at 520 $g$ for $15 \mathrm{~min}$, and the supernatants were either injected at once or stored at $4^{\circ} \mathrm{C}$ for several days. An aliquot from each flask was cultured in thioglycollate broth to confirm sterility. All experiments in which cultures were not sterile were discarded. In each experiment a control flask of white cells in serum-buffer was incubated, as well as various experimental flasks. Supernatants from all flasks in each experiment were usually injected into the same two rabbits.

Rabbit lenkocytes. Rabbit blood was obtained by cardiac puncture, and processed as described for human blood. Techniques for preparing spleen and lymph node cells have been described previously (11). Briefly, tissues were minced, forced through a wire gauze with saline, and white cells were counted. I.ung cells were obtained by a modification (17) of the technique of Myrvik, I.cake, and Fariss (18). All mononuclear cells in these experiments were obtained from rabbits previously infected with BCG.

Leukocytes were suspended in KRP buffer and $15 \%$ normal rabbit serum for incubation, with added glucose and penicillin as described previously. $1-2 \times 10^{8}$ cells were usually added to each flask, in a total volume of $15 \mathrm{ml}$. Heat-killed staphylococcus albus, prepared as described previously (10), was added to one incubation flask for some experiments, in a ratio of $30-50$ bacteria per white cell.

Fever index. The area under fever curves $2 \mathrm{hr}$ after injection was measured as previously described (19).

\section{RESULTS}

To determine whether etiocholanolone could initiate release of pyrogen by leukocytes in vitro, we 


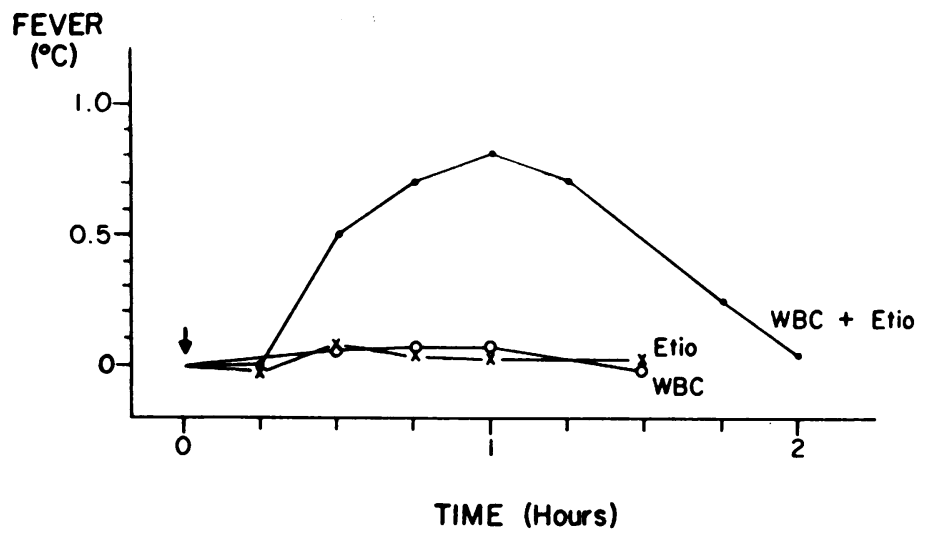

FIGURE 1 Febrile responses in one rabbit to injection of supernatants from $5.0 \times 10^{7}$ white cells $(W B C)$, incubated with or without etiocholanolone (Etio) at a final concentration of $39 \mu \mathrm{g} / \mathrm{ml}$, or from etiocholanolone incubated alone.

incubated human white cell preparations for $18 \mathrm{hr}$ with a buffered solution of etiocholanolone and $15 \%$ serum. Control leukocytes were incubated in a serum-buffer medium alone. The supernatants were removed, and from each flask a volume derived from the same number of white cells $\left(4-5 \times 10^{i}\right)$ was injected into each rabbit. The results from a typical experiment are shown in Fig. 1. Supernatants from the leukocytes incubated with etiocholanolone were pyrogenic, whereas controls containing either leukocytes alone or etiocholanolone incubated without leukocytes were inactive. The shape of this fever curve, including its early onset and rapid defervescence, resembles the curves produced by injection of both rabbit (20) and human (10) leukocyte pyrogen. These results were repeatedly confirmed. In a series of 25 consecutive experiments, etiocholanolone failed to induce significant pyrogen only twice. In two other experiments of this series, the supernatant derived from leukocytes incubated in serum-buffer alone contained pyrogen $\left(>0.3^{\circ} \mathrm{C}\right.$ average maximum fever). This occasional occurrence of "spontaneous" activation has been reported previously (10). All other experiments in the series gave results which were similar to those shown in Fig. 1. The data from these experiments are averaged in Table I. These findings, then, suggest that a leukocyte pyrogen is produced when human white blood cells are incubated in the presence of etiocholanolone.

The following controls were devised to exclude the possible role of endotoxin contamination. Solutions of etiocholanolone were injected in volumes of $30 \mathrm{ml}$ or more and were nonpyrogenic even when preincubated with $15 \%$ rabbit serum at $37^{\circ} \mathrm{C}$ for $1 / 2 \mathrm{hr}$ to potentiate the action of any endotoxin that might be present. The possible contribution of endotoxin from other sources would appear to be eliminated by the negative cultures of all tested material and by the absence of pyrogen in the supernatant from control leukocytes. Injections of etiocholanolone incubated alone as controls in various experiments were uniformly nonpyrogenic. These curves have been omitted from subsequent figures for simplicity.

In order to confirm that the pyrogen being produced during incubation of white cells with etiocholanolone was a protein, like the endogenous pyrogens previously described of rabbit (21) and human (10) origin, we attempted to inactivate

TABLE I

Human Blood Leukocytes Incubated with Etiocholanolone

\begin{tabular}{lccc}
\hline & $\begin{array}{c}\text { No. of } \\
\text { experiments }\end{array}$ & WBC* & $\begin{array}{c}\text { Maximum fever } \\
\left({ }^{\circ} \mathrm{C}\right) \ddagger\end{array}$ \\
\hline WBC & 21 & $47.0 \pm 1.7 \S$ & $0.06 \pm 0.017(31) \|$ \\
$\begin{array}{l}\text { WBC plus } \\
\text { etiocholanolone }\end{array}$ & 21 & $47.0 \pm 1.7$ & $0.75 \pm 0.047(36)$
\end{tabular}

* Average number of leukocytes from which supernatant was derived for each injection.

$\ddagger$ Average temperature elevation above base line.

$\$ \mathrm{SE}$ of mean.

|| Numbers of rabbits injected. 


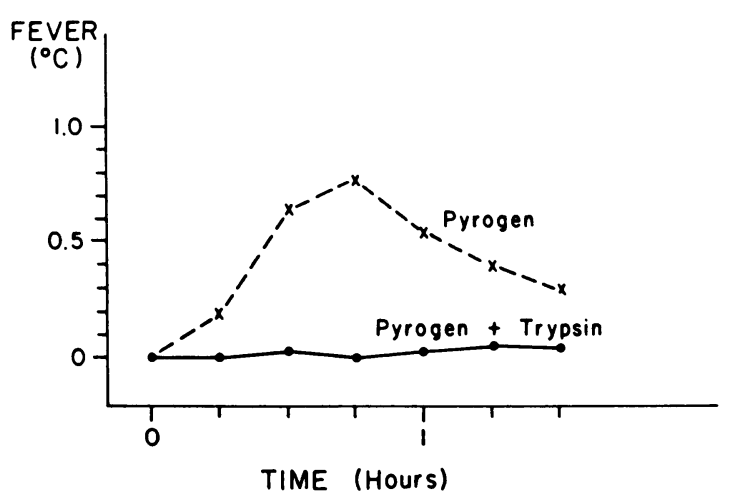

FIgURE 2 Average fevers in rabbits after injection of preformed etiocholanolone pyrogen, incubated in Tris buffer, $\mathrm{pH} 8.4$, with and without $3 \mathrm{mg}$ of trypsin per injection. In this and the following figures, unless otherwise stated, each curve represents the average responses of two rabbits, and the same rabbits received all injections for each experiment.

preformed "etiocholanolone pyrogen" by trypsin and pronase. Supernatant from an $18 \mathrm{hr}$ incubation of leukocytes and etiocholanolone was divided into two parts. To each was added $0.15 \mathrm{~m}$ Tris buffer $\mathrm{pH} 8.4, \mathrm{CaCl}_{2}$ to a final concentration of $10^{-3} \mathrm{M}$, and to one flask $6 \mathrm{mg}$ of trypsin. ${ }^{4}$ In other experiments, $0.5 \mathrm{mg}$ of pronase $^{5}$ was added in-

4 Trypsin, $2 \times$ crystallized (salt-free), Nutritional Biochemicals Corp., Cleveland, Ohio.

5 Pronase, B grade, Calbiochem, Los Angeles, Calif. The enzyme in buffer was preincubated for $2 \mathrm{hr}$ before use. stead of trypsin. Total volumes were $12-15 \mathrm{ml}$. After overnight incubation at $37^{\circ} \mathrm{C}$, both control and enzyme-treated samples were tested in two rabbits. The results of one experiment with trypsin are given in Fig. 2. Identical results were obtained with pronase. Since both enzymes removed the pyrogenic activity from such supernatants, "etiocholanolone pyrogen" appears to have an essential protein nature like other endogenous pyrogens.

Since phagocytosis activates leukocytes to release pyrogen (10), it seemed essential to show that the activating properties of this preparation of etiocholanolone were not due to the presence of very small particles of crystalline steroid. The following experiment was designed to test this hypothesis. A solution of etiocholanolone was prepared in the usual way (see Methods). After filtration, a portion of this solution was spun at $105,000 \mathrm{~g}$ for $2 \mathrm{hr}$ in a Spinco Model L Ultracentrifuge, in tubes which had been autoclaved for $1 \frac{1}{2} \mathrm{hr}$ to inactivate any endotoxin. The supernatant was then carefully removed and incubated with white cells, along with an unspun aliquot of the original filtrate. As shown in Fig. 3, there was equal pyrogen production from cells incubated with both samples. Since centrifugation at this speed should have removed all particles of greater than 400,000 molecular weight (22), it is extremely unlikely that the presence of microcrystals of steroid could be responsible for the activation of leukocytes in our system.

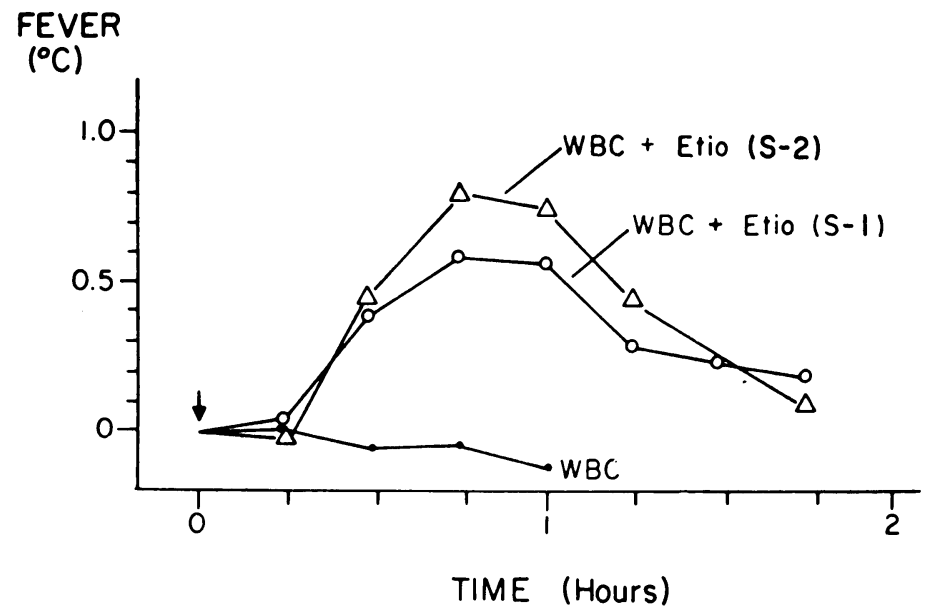

FIgURE 3 Average fevers in rabbits after injection of supernatants from $5.0 \times 10^{7}$ white cells $(W B C)$ incubated alone, with a solution of etiocholanolone $39 \mu \mathrm{g} / \mathrm{ml}(S-1)$, or supernatant of the same solution after centrifugation at $105,000 \mathrm{~g}$ for $2 \mathrm{hr}(S-2)$. 
It seemed possible that changes had occurred in steroid structure during either its preparation or incubation with leukocytes. Chromatography, melting points, and infrared spectroscopy, as well as labeled etiocholanolone, were used to examine this possibility. No detectable change occurred in the steroid either after autoclaving or after an 18-hr incubation with white cells. Thus, a buffer solution of etiocholanolone, containing about $30 \mu \mathrm{g} / \mathrm{ml}$, appeared to be capable of activating white cells to release pyrogen.

Since a closely related steroid, androsterone, which differs only in having a $5 \alpha$-configuration, has been reported to be usually nonpyrogenic in human injection studies (3), attempts were made to induce production of pyrogen in the in vitro system with solutions of this compound. Androsterone solutions were prepared in the same way as were those of etiocholanolone. In seven experiments, in which several different preparations of steroid were used, varying in concentration from 14 to $40 \mu \mathrm{g} / \mathrm{ml}$, androsterone was completely nonpyrogenic five times. In two experiments, leukocytes incubated with androsterone released small amounts of pyrogen. One experiment is shown in Fig. 4. In this experiment both etiocholanolone and androsterone were present in nearly equal concentrations. These results indicate that the two steroids, etiocholanolone and androsterone, have different capacities for inducing in vitro pyrogen release from leukocytes under these conditions.

In the next group of experiments, the relation between the release of pyrogen and the concentra-

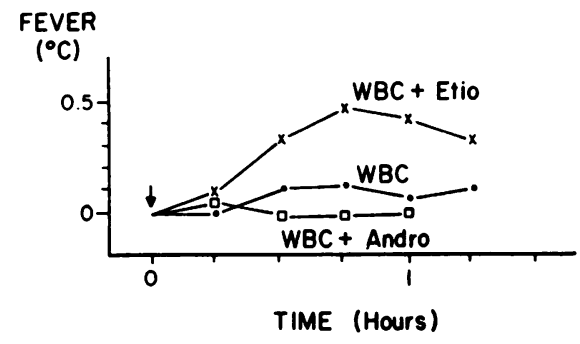

Figure 4 Average fevers in rabbits after injection of supernatants from $4.0 \times 10^{7}$ white cells $(I V B C)$ incubated alone, with $29 \mu \mathrm{g} / \mathrm{ml}$ androsterone, or $27 \mu \mathrm{g} / \mathrm{ml}$ etiocholanolone.

tion of etiocholanolone was examined. The usual concentration of a buffer-saturated solution of etiocholanolone was $20-40 \mu \mathrm{g} / \mathrm{ml}$. Varying dilutions of steroid were used in four experiments, one of which is shown in Fig. 5. When the concentration was decreased 2- to 3-fold, production of pyrogen was sharply reduced in all experiments. Production was usually maximal with levels of $20-30 \mu \mathrm{g} / \mathrm{ml}$ (the highest concentrations tested), but when the concentration of steroid was reduced to $10 \mu \mathrm{g} / \mathrm{ml}$ or less, little or no pyrogen was evolved.

Since one of the unusual characteristics of the pyrogenic steroids is their ability to evoke fever only in man, it was of interest to determine whether leukocytes from rabbits could release pyrogen in vitro. For these experiments, rabbit and human cells were prepared in the same way, and the solutions of steroid used were known to be effective when incubated with human cells.

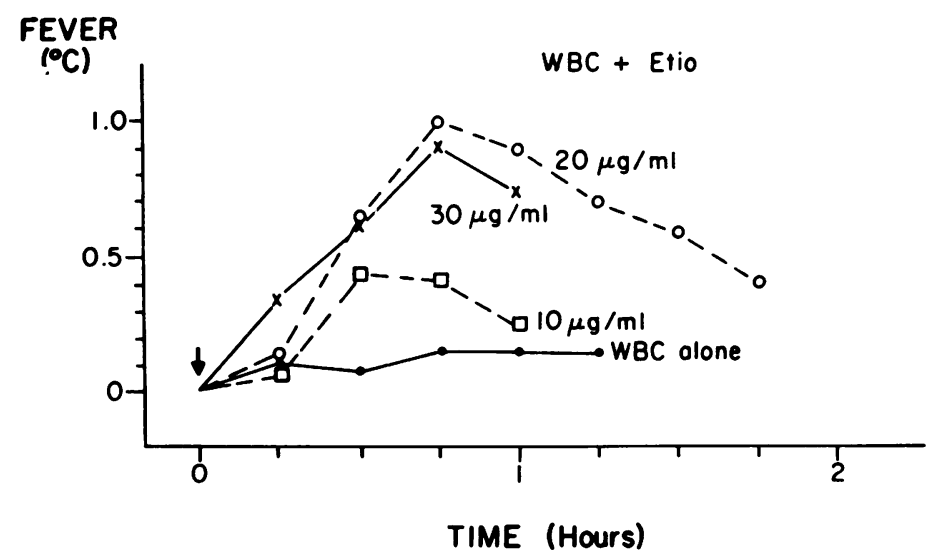

FIGURE 5 Average fevers in rabbits after injection of supernatants from $5.5 \times 10^{7}$ white cells $(W B C)$ incubated alone or with varying concentrations of etiocholanolone (Etio). 


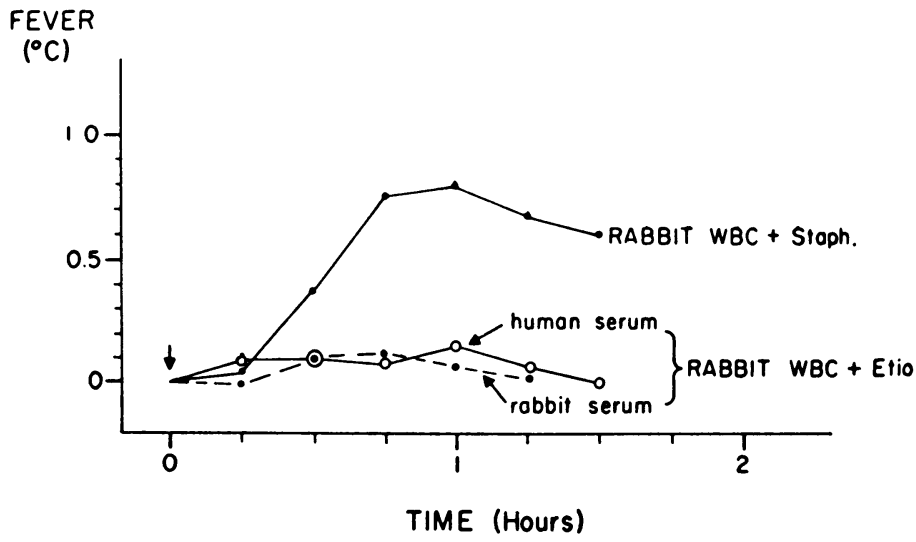

FIGURE 6 Average fevers in rabbits after injection of supernatants from $5.5 \times 10^{7}$ rabbit white cells $(W B C)$ incubated with $15 \%$ human or rabbit serum and etiocholanolone (Etio) $35 \mu \mathrm{g} / \mathrm{ml}$, or $2.25 \times 10^{7}$ WBC incubated in $15 \%$ rabbit serum with $2.6 \times 10^{8}$ heat-killed staphylococci.

Despite these conditions, four attempts to release pyrogen from rabbit leukocytes with etiocholanolone were unsuccessful. In one experiment, shown in Fig. 6, portions of a preparation of rabbit leukocytes were incubated with steroid or with heatkilled staphylococci. It is apparent that etiocholanolone did not activate the rabbit cells, whether these were incubated in rabbit or human serum. The rabbit cells in this experiment were clearly able to produce pyrogen however since addition of heat-killed staphylococci to one aliquot of cells resulted in release of pyrogen (see upper curve, Fig. 6). The inability of human serum to

TABLE II

Rabbit Mononuclear Cells Incubated with Etiocholanolone or Heat-Killed Staphylococci

\begin{tabular}{|c|c|c|c|}
\hline \multirow[b]{2}{*}{ Cell source } & \multicolumn{3}{|c|}{ Maximum fever $\left({ }^{\circ} \mathrm{C}\right)^{*}$} \\
\hline & $\begin{array}{l}\text { Cells } \\
\text { alone }\end{array}$ & $\begin{array}{l}\text { Cellsł } \\
\text { plus } \\
\text { etiocho- } \\
\text { lanolone }\end{array}$ & $\begin{array}{c}\text { Cells } \neq \\
\text { plus } \\
\text { staphy- } \\
\text { lococci }\end{array}$ \\
\hline Lung & $0.0(3) \S$ & $0.05 \|(2)$ & $0.45(2)$ \\
\hline Lung & $0.02(2)$ & 0.05 (1) & $1.05(2)$ \\
\hline Lung & $0.0(2)$ & $0.05 \|(2)$ & 1.1 (2) \\
\hline Spleen & $0.05(1)$ & $0.0 \quad(1)$ & 0.9 (1) \\
\hline Spleen & $0.05(2)$ & $0.05 \quad(2)$ & $1.05(2)$ \\
\hline Lymph node & $0.15(2)$ & 0.0 & 0.8 (2) \\
\hline Lymph node & 0.0 (2) & $0.05(2)$ & 0.4 (2) \\
\hline
\end{tabular}

* Average temperature elevatior above base line. $\pm 1 \times 10^{8}$ cells incubated per rabbit injection. $\$$ Numbers of rabbits injected.

|| Cells plus 11-keto etiocholanolone. induce activation of rabbit cells by etiocholanolone was confirmed in another experiment.

Additional studies on rabbit cells were carried out with preparations of mononuclear cells from lungs, lymph nodes, and spleen. In no case could pyrogen be detected in the supernatants of cells incubated with etiocholanolone, although other aliquots of the same cells produced large amounts of pyrogen when heat-killed staphylococci were added. Results of these experiments with rabbit mononuclear cells are given in Table II. Aliquots of cells from three sources were incubated for $18 \mathrm{hr}$ alone, with etiocholanolone, or with heatkilled staphylococci. All supernatants were injected into the same rabbit or rabbits in each experiment; in two cases, an additional rabbit received one or more supernatants. In two experiments, iymph node preparations did not release pyrogen in response to either stimulus, and these results are omitted. As indicated in the table, two preparations of lung cells were incubated with 11-keto etiocholanolone, a steroid preparation with high pyrogenic activity when added to human cells, ${ }^{8}$ in place of etiocholanolone. The concentration of this steroid was $280 \mu \mathrm{g} / \mathrm{ml}$.

Intravenous injection of large amounts of etiocholanolone into rabbits, whether given as a single injection, or as a $12 \mathrm{hr}$ infusion containing 2.9-3.8

${ }^{6}$ Dillard, G. M., and P. Bodel. Studies on Steroid fever. II. Pyrogenic activity in vitro of some endogenous steroids of man. In manuscript. 


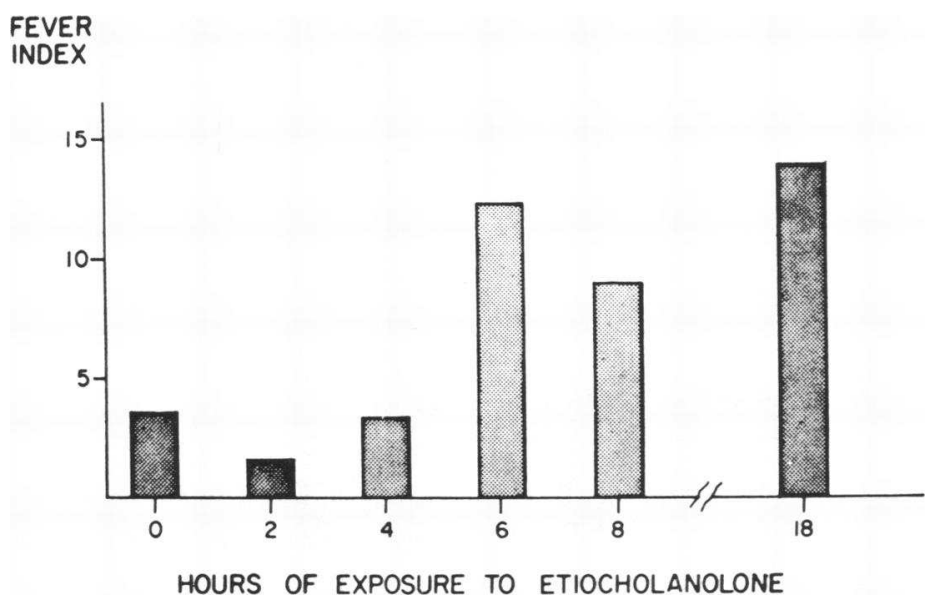

FIgURE 7 Average fever indexes of rabbits after injection of supernatants derived from 18-hr incubations of $6.3 \times 10^{7}$ white cells. Each aliquot of cells was exposed to etiocholanolone $32 \mu \mathrm{g} / \mathrm{ml}$ for varying times before centrifugation and further incubation in serum buffer.

$\mathrm{mg}$ of steroid, did not produce fever. These last data confirm the work of others who have used somewhat different solvents and injection schedules (4). ${ }^{7}$

The long latent period (usually $4-6 \mathrm{hr}$ ) that follows the injection of steroid in man is an unusual feature of this form of experimental fever. Further experiments were carried out with the in vitro system to determine how long the leukocyte requires exposure to etiocholanolone before pyrogen production is initiated. The results of a typical experiment are shown in Fig. 7. Fever indexes rather than fever curves are plotted for convenience. Control leukocytes in this experiment were incubated for $18 \mathrm{hr}$ in a serum-buffer medium. Experimental leukocytes were first incubated with etiocholanolone for varying intervals, then centrifuged, and the supernatant was removed. The cells were then suspended in fresh serum-buffer for the remainder of $18 \mathrm{hr}$, after which the second supernatant was removed. The first and second supernatants were combined for injections; thus, each fever index shown in Fig. 7 represents the total pyrogen released during $18 \mathrm{hr}$ for each preparation. Cells exposed to etiocholanolone for only 2 or $4 \mathrm{hr}$, like control cells, did not release a significant amount of pyrogen. However, exposure of the cells to steroid for 6,8 , or $18 \mathrm{hr}$ all appeared to be equally effective in stim-

TCohn, G. L., and E. Atkins. Unpublished observations. ulating the cells to release pyrogen. In six other similar experiments the time of exposure required for stimulation varied between 4 and $8 \mathrm{hr}$. Only one of five experiments in which the $4 \mathrm{hr}$ incubation time was tested showed pyrogen release after $4 \mathrm{hr}$ of exposure, whereas four of six experiments in which cells were tested after $6 \mathrm{hr}$ of incubation showed pyrogen release. From these studies it seems clear that exposure to a solution of etiocholanolone for a number of hours is required in order for the leukocytes to become activated.

Since the blood leukocyte preparations in these studies contain several different cell types, and since human mononuclear cells are now known to release pyrogen under certain conditions (23), it was of interest to determine which cell in the leukocyte preparations was responsible for production of pyrogen. In two experiments of different design, blood mononuclear cells were clearly implicated as one source of pyrogen.

In the first experiment, blood leukocytes were obtained on two occasions from a patient with chronic agranulocytosis. Differential counts revealed only $3 \%$ eosinophils, with the remainder of the leukocytes either monocytes or lymphocytes. When the white cells from this patient were incubated with etiocholanolone, definite production of pyrogen occurred. Sufficient pyrogen was released by $3-7 \times 10^{8}$ monocytes to cause an average fever of $0.7^{\circ} \mathrm{C}$ in five rabbits. The fever curves in these 


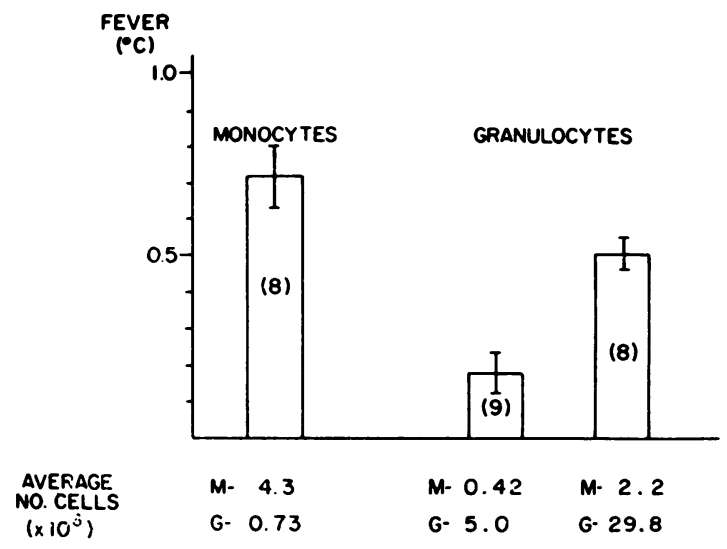

Figure 8 Average maximum fevers in rabbits after injection of supernatants from various white cell preparations incubated with etiocholanolone. The average numbers of monocytes $(M)$ and granulocytes $(G)$ contributing to the supernatants is given below each bar. The number of recipient rabbits is given in parentheses within each bar. SE of mean is indicated. All blood cells were obtained from normal donors except in two experiments (five recipients) included in the left-hand bar in which leukocytes were from a patient with chronic agranulocytosis.

rabbits exactly resembled those of normal blood leukocyte pyrogen (see, for example, Fig. 1). In the second experiment, a preparation of monocytes and lymphocytes was obtained from normal blood by differential centrifugation in human serum albumin (see Methods). Such preparations of mononuclear cells, containing less than $10 \%$ granulocytes, were shown on three occasions to release pyrogen following incubation with etiocholanolone. The total number of granulocytes in these preparations was less than $1.5 \times 10^{6}$, a level well below the minimum of these cells required for significant production of pyrogen (see below). Results from these two types of experiments with mononuclear cells are summarized in the left-hand bar in Fig. 8.

It seems likely, then, that mononuclear cells can release pyrogen following incubation with etiocholanolone. Calculation of the per cent of monocytes and lymphocytes in these various preparations indicates that release of pyrogen varied directly with the numbers of monocytes, and was easily detectable when as few as $5 \times 10^{\circ}$ monocytes were present. The absolute number of lymphocytes, however, varied from less than 1-18 $\times 10^{6}$ in preparations with similar pyrogenicity.
Such evidence, although indirect, suggests that the monocyte is the important cell in these preparations.

Several experiments were designed to investigate the action of etiocholanolone on human granulocytes. The results of some of these studies are summarized in the right half of Fig. 8. Normal blood cells, containing $60-70 \%$ granulocytes, released little or no pyrogen when incubated with etiocholanolone in dosages of 3-6 $6 \times 10^{6}$ granulocytes. When the numbers of granulocytes were increased to about $3 \times 10^{7}$, fevers of about $0.5^{\circ} \mathrm{C}$ were produced in four experiments, in which numbers of monocytes were between 1.5 and $3.5 \times 10^{\circ}$. Comparison with fevers induced by $4-6 \times 10^{6}$ monocytes (see left half of Fig. 8) indicates that etiocholanolone stimulates mononuclear cells to a much greater extent than it does granulocytes. From results of several experiments in which numbers of monocytes were very low, however, it is possible that granulocytes can also release pyrogen after incubation with steroid. Further studies will be needed to confirm this inference.

\section{DISCUSSION}

Etiocholanolone and its isomer, androsterone, are naturally occurring steroids which are formed as end products of androgen metabolism. Studies of the concentration of unconjugated etiocholanolone in normal plasma (24) have indicated that there is approximately $1 \mu \mathrm{g} / 100 \mathrm{ml}$ of plasma. When etiocholanolone is injected $(25,26)$, it is rapidly conjugated, cleared from plasma, and excreted in the urine in conjugated form, primarily as the glucosiduronate.

Etiocholanolone has no apparent androgenic activity, unlike its principal metabolic precursors, but it has antitumor activity in certain lymphomas (27), and recently has been shown to cause porphyrin release from liver cells (28). The discovery that etiocholanolone (1) and many other similar steroids (5) are pyrogenic suggested that abnormalities of steroid production or turnover might give rise to some clinical fevers. There is some evidence to support this hypothesis $(8,9)$. However, the exact role of these compounds in periodic fevers has not been clarified.

The studies reported here indicate that etiocholanolone can activate human blood leukocytes to release an endogenous pyrogen in vitro. Al- 
though it is not known whether this material is identical to leukocyte pyrogen elicited by other stimuli (10), the two agents resemble each other closely in all tested biologic activities. For example, both pyrogens elicit in rabbits a prompt monophasic fever which is usually maximal at 45-60 min and rapidly defervesces. This fever curve differs from those observed with many other pyrogens (7). Further, both agents are stable for weeks when stored at $4^{\circ} \mathrm{C}$, and both are inactivated by trypsin. Finally, rabbits do not develop tolerance to repeated injections of these leukocyte pyrogens, as they do to a number of microbial products.

In the following respects, release of endogenous pyrogen by human leukocytes exposed in vitro to etiocholanolone resembles the steroid fever that follows injection of etiocholanolone into human volunteers.

First, as reported by Kappas and Palmer (3), injection of androsterone, the $5 \alpha$-analogue of etiocholanolone, into volunteers did not elicit fever, except occasionally after repeated injections. In our in vitro model, androsterone was tested under the same conditions as etiocholanolone and was not pyrogenic in most experiments. Studies of other steroids, both "pyrogenic" and "nonpyrogenic" by injection studies, are reported in another paper, ${ }^{8}$ and confirm the specificity of the reaction.

Second, in our studies rabbit leukocytes failed to release pyrogen when exposed to etiocholanolone. This was true whether or not human serum was present, or whether various mononuclear cell preparations were used. Similarly, this steroid has repeatedly failed to induce fever when injected in a variety of animals (4), suggesting that steroid fever occurs only in man. Our in vitro studies are at least consistent with this hypothesis, although experiments with leukocytes from other species would provide more evidence. Since endogenous pyrogen from dog leukocytes does not produce fever in rabbits (29), however, studies of pyrogen release from leukocytes of additional animals will only be meaningful when it is established that these pyrogens are active in rabbits.

A long period of incubation with steroid was required in order to activate leukocytes in our experi-

8 Dillard, G. M., and P. Bodel. Studies on steroid fever. II. Pyrogenic activity in vitro of some endogenous steroids of man. In manuscript. ments. This unusual feature seems to correlate well with the long latent period described in vivo before onset of fever. By contrast, when endotoxin is added to rabbit leukocytes in vitro, inculation of the cells for only $5 \mathrm{~min}$ or less is sufficient to induce activation (30). Similarly, endotoxin causes a prompt fever after injection in both rabbit and man (7). The activation of human cells by phagocytosis also occurs within $1 \mathrm{hr}$ after bacteria are added. ${ }^{9}$ The reasons for the delay in activation of leukocytes by etiocholanolone, which is presumably related to the mode of action of the steroid on the white cell, are presently unknown. The steroid may act on a different cell than the one stimulated by endotoxin or by phagocytosis, or it may activate the cell by different pathways. It seems very unlikely that such a time delay in vitro is due to a product of steroid conversion, since no change in composition of radioactive steroid could be demonstrated after incubation with leukocytes.

A relationship between steroid fever and leukocytes is suggested by previous observations that most pyrogenic steroids produce marked local inflammation and leukocytosis (6), and that leukopenic patients injected with etiocholanolone react with little inflammation or fever (31). However, it would be premature to propose a direct relationship between our in vitro studies and such injection experiments in human volunteers. Studies in rabbits have shown that leukocytes from lung, lymph node, and spleen are all capable of pyrogen release (17), as are monocytes from peritoneal exudates (32), and since the sites to which steroid is carried after injection are not known, it is possible that blood leukocytes play no role in the fever induced by this agent. These studies do suggest, however, that steroid fever in man is mediated by an endogenous pyrogen released from leukocytes of some kind. Since pyrogenic steroids release lysosomal enzymes from suspensions of rabbit leukocyte granules and liver lysosomes (33), their ability to activate human cells may also depend upon alterations in membrane permeability. Changes in membrane structure probably precede release of endogenous pyrogen in other experimental models (7).

The contribution of steroids such as etiocholanolone to clinical fevers is still not clearly defined.

${ }^{9}$ Bodel, P., and E. Atkins. Unpublished observations. 
The capacity of this steroid to activate leukocytes to release pyrogen, however, indicates that this steroid and related compounds may have important biological activities in man, including the capacity to induce fever. It is likely that further studies of the action of pyrogenic steroids on cells may lead to a better understanding of the role of these compounds in health and disease.

\section{ACKNOWLEDGMENTS}

We thank Dr. Elisha Atkins, in whose laboratory most of this work was done, for his interest, encouragement, and invaluable advice, and Dr. Philip Bondy for his interest and support. We also thank David Kelly and Mrs. James Wechsler for excellent technical assistance.

This work was supported by grants (AI-01564 and AM-00254) from the U. S. Public Health Service.

\section{REFERENCES}

1. Kappas, A., L. Hellman, D. K. Fukushima, and T. F. Gallagher. 1957. The pyrogenic effect of etiocholanolone. J. Clin. Endocrinol. Metab. 17: 451.

2. Kappas, A., P. B. Glickman, and R. H. Palmer. 1960. Steroid fever studies: Physiological differences between bacterial pyrogens and endogenous steroid pyrogens of man. Trans. Assoc. Am. Physicians. 73: 176.

3. Kappas, A., and R. H. Palmer. 1963. Selected aspects of steroid pharmacology. Pharmacol. Rev. 15: 123.

4. Palmer, R. H., B. Ratkovits, and A. Kappas. 1961. Steroid pyrogen studies in laboratory and domestic animals. J. Appl. Physiol. 16: 345.

5. Kappas, A., W. Soybel, P. Glickman, and D. K. Fukushima. 1960. Fever-producing steroids of endogenous origin in man. Arch. Internal. Med. 105: 701.

6. Glickman, P. B., R. H. Palmer, and A. Kappas. 1964. Steroid fever and inflammation. Arch. Internal Med. 114: 46 .

7. Atkins, E., and E. S. Snell. 1965. Fever. In The Inflammatory Process. B. W. Zweifach, L. Grant, ancं R. T. McCluskey, editors. Academic Press Inc., N. Y. 495.

8. Bondy, P. K., G. L. Cohn, and C. Castiglione. 1960. Etiocholanolone fever; A clinical entity. Trans. Assoc. Am. Physicians. 73: 186.

9. Bondy, P. K., G. L. Cohn, and P. B. Gregory. 1965. Etiocholanolone fever. Medicine. 44: 249.

10. Bodel, P., and E. Atkins. 1966. Human leukocyte pyrogen producing fever in rabbits. Proc. Soc. Exptl. Biol. Med. 121: 943.

11. Atkins, E., and C. Heijn, Jr. 1965. Studies on tuberculin fever. III. Mechanisms involved in the release of endogenous pyrogen in vitro. J. Exptl. Med. 122: 207.

12. Fallon, H. J., E. Frei, III, J. D. Davidson, J. S. Trier, and D. Burk. 1962. Leucocyte preparations from human blood: Evaluation of their morphologic and metabolic state. J. Lab. Clin. Med. 59: 779.

13. Bennett, W. E., and Z. A. Cohn. 1966. The isolation and selected properties of blood monocytes. J. Exptl. Med. 123: 145.

14. Lakshmanan, T. K., and S. Lieberman. 1954. An improved method of gradient elution chromatography and its application to the separation of urinary ketosteroids. Arch. Biochcm. Biophy's. 53: 258.

15. Edwards, R. W. H. 1958. Steroids. In Chromatographic and Electrophoretic Techniques. I. Smitl, editor. William Heineman, London. 1: 428.

16. Wilzbach, K. E. 1957. Tritium-labeling by exposure of organic compounds to tritiun gas. J. Am. Chem. Soc. 79: 1013.

17. Atkins, E., P. Bodel, and I. Francis. 1967. Release of an endogenous pyrogen in itro from rabbit mononuclear cells. J. Exptl. Med. 126: 357.

18. Myrvik, Q. N., E. S. Leake, and B. Fariss. 1961. Studies on pulmonary alveolar macrophages from the normal rabbit: A technique to procure them in a high state of purity. J. Immunol. 86: 128 .

19. Bodel, P. T., and E. Atkins. 1965. Studies in staphylococcal fever. V. Staphylococcal filtrate pyrogen. Yale J. Biol. Mcd. 38: 282.

20. Bennett, I. I.., Jr., and P. B. Beeson. 1953. Studies on pathogenesis of fever. II. Characterization of feverproducing substances from polymorphonuclear leukocytes and from fluid of sterile exudates. J. Exptl. Mcd. 98: 493.

21. Rafter, G. W., R. D. Collins, and W. B. Wood. 1960. Studies on the pathogenesis of fever. VII. Preliminary chemical characterization of leucocytic pyrogen. $J$. Exptl. Med. 111: 831 .

22. 1952. Spinco Technical Manual, Ultracentrifuge Model L. Specialized Instruments Corp., Belmont, Calif.

23. Bodel, P., and E. Atkins. 1967. Release of endogenous pyrogen by human monocytes. Neze Engl. J. Mcd. 276: 1002.

24. Cohn, G. L., P. K. Bondy, and C. Castiglione. 1961. Studies on pyrogenic steroids. I. Separation, identification and measurement of unconjugated dehydroepiandrosterone, etiocholanolone and androsterone in human plasma. J. Clin. Invest. 40: 400.

25. Kappas, A., L. Hellman, D. K. Fukushima, and T. F. Gallagher. 1958. The thermogenic effect and metabolic fate of etiocholanolone in man. J. Clin. Endocrinol. Mctab. 18: 1043.

26. Bondy, P. K., G. L. Cohn, and P. B. Gregory. 1965. Etiocholanolone fever. Medicine. 44: 249.

27. Hellman, L. Steroids. In Clinical Endocrinology. E. B. Astwood, editor. Grune and Stratton, N. Y. In press.

28. Levere, R., A. Kappas, and S. Granick. 1967. The induction of hemoglobin formation in erythroid cell culture by $5 \beta-\mathrm{H}$ steroid metabolites. J. Clin. Invest. 46: 1084. 
29. Petersdorf, R. G., and I. L. Bennett, Jr. 1957. Studies on the pathogenesis of fever. VII. Comparative observations on the production of fever by inflammatory exudates in rabbits and dogs. Bull. Johns Hopkins Hosp. 100: 277.

30. Snell, E. S., and E. Atkins. 1967. Interactions of gram-negative bacterial endotoxin with rabbit blood in vitro. Am. J. Physiol. 212: 1103.

31. Shulman, J. A., W. L. Herrmann, and R. G. Peters- dorf. 1964. Experimental etiocholanolone fever. $J$. Clin. Endocrinol. Metab. 24: 1136.

32. Hahn, H. H., D. C. Char, W. B. Postel, and W. B. Wood, Jr. 1967. Studies on pathogenesis of fever. XV. Production of endogenous pyrogen by peritoneal macrophages. J. Iixpll. Mcd. 126: 385.

33. Weissmann, G. 1965. Studies of lysosomes. VI. The effect of neutral steroids and bile acids on lysosomes in vitro. Biochem. Pharmacol. 14: 525. 